Oscar Alberto Morales*, Bexi Perdomo, Daniel Cassany, Rosa María Tovar and Élix Izarra

\title{
Linguistic structures and functions of thesis and dissertation titles in Dentistry
}

https://doi.org/10.1515/les-2020-0003

\begin{abstract}
Titles play an important role in genre analysis. Cross-genre studies show that research paper and thesis titles have distinctive features. However, thesis and dissertation titles in the field of dentistry have thus far received little attention. Objective: To analyze the syntactic structures and their functions in English-language thesis and dissertation titles in dentistry. Methodology: We randomly chose 413 titles of English-language dentistry theses or dissertations presented at universities in 12 countries between January 2000 and June 2019. The resulting corpus of 5,540 running words was then analyzed both qualitatively and quantitatively, the two complementary focuses being grammatical structures and their functions. Results: The average title length was 13.4 words. Over half of the titles did not include any punctuation marks. For compound titles, we found that colons, dashes, commas, and question marks were used to separate the different components, colons being the most frequent. Four syntactic structures (nominal phrase, gerund phrase, full-sentence, and prepositional phrase) were identified for single-unit titles. Single-unit nominal phrase titles constituted the most frequent structure in the corpus, followed by compound titles. Four particular rhetorical combinations of compound title components were found to be present
\end{abstract}

Notes: All examples have been copied verbatim from the original text; the original spelling, punctuation, and structure is therefore reproduced here intact.

\footnotetext{
*Kontaktperson: Oscar Alberto Morales, School of Dentistry, Universidad de Los Andes, Mérida, Venezuela; School of Dentistry, Universidad de Los Hemisferios, Quito, Ecuador, Paseo de la Universidad 300, Iñaquito Alto, 170135, Quito Ecuador, E-Mail: oamorales@profesores.uhemisferios.edu.ec

Bexi Perdomo, School of Dentistry, Universidad de Los Andes, Mérida, Venezuela, E-Mail: bexi.de.flores@gmail.com

Daniel Cassany, Dept. of Translation and Language Sciences, Universitat Pompeu Fabra, Barcelona, Spain, E-Mail: daniel.cassany@upf.edu

Rosa María Tovar, Faculty of Education Sciences, Universidad de Carabobo, Valencia, Venezuela, E-Mail: rosamtovar@gmail.com

Élix Izarra, School of Dentistry, Universidad de Los Andes, Mérida, Venezuela,

E-Mail: izarraelix@gmail.com
} 
throughout the corpus. Conclusions: Titles of dentistry theses and dissertation in English echo the content of the text body and make an important contribution to fulfilling the text's communicative purposes. Thus, teaching research students about the linguistic features of thesis titles would be beneficial to help them write effective titles and also facilitate assessment by teachers.

Keywords: Dentistry, dissertation titles, lexico-grammatical analysis, linguistic structure, thesis titles

\section{Introduction}

Ever since Swales published his foundational book on genre analysis in 1990, there has been growing interest in researching discourse genres. While some of this research has analyzed the rhetorical structures and main sections in published research papers, case reports, and review papers (Swales 1990, Yang/ Allison 2003), other studies have focused on the distinctive linguistic and rhetorical features of these genres, such as hedges, intensifiers, voice, tense, reporting verbs, or modals (Malcolm 1987, Hawes/Thomas 1997, Swales 1990).

In the last three decades, culminating text genres written by students have received increased attention in different languages and disciplines (Paltridge 1997, Bunton 1998, Thompson 2001, Venegas/Zamora/Galdames 2016). While in some cases the focus has been on the rhetorical structures and main sections in theses and dissertations (Paltridge 1997, Bunton 1998, Parry 1998, Hewitt/Lago 2010, Paltridge/Starfield 2007), other studies have analyzed the moves that occur in particular sections, namely introduction (Soler-Monreal/Carbonell-Olivares/ Gil-Salom 2011), statement of the problem (Nimehchisalem/Tarvirdizadeh/Paidary/Hussin 2016), literature review (Kwan 2006, Flowerdew/Forest 2009), methods (Cotos/Huffman/Link 2017), results (Basturkmen 2009), discussion (Hewitt/ Lago 2010, Samraj 2013, Lee/Casal 2014, Flowerdew 2015), and conclusions (Trafford/Leshem/Bitzer 2014, Bunton 2005). More recently, titles have also become the focus of researchers' attention (Afful/Akoto 2010, Gesuato 2009, Jalilifar 2010, Soler 2018).

Titles of academic texts in different languages, disciplines, and genres have been examined. Most research on titles has focused on scientific papers such as research articles (Alcaraz-Ariza/Salager-Meyer 2012, Anthony 2001, Entralgo/Salager-Meyer/Luzardo 2014, Haggan 2004, Hartley 2007a, 2007b, Nagano 2015), review papers (Soler 2007, Morales/Perdomo/Cassany/Izarra 2020, Morales/Perdomo under review), conference presentations (Yakhontova 2002, Afful 2017), or posters and short communications (Cianflone 2012, 2013). 
Cross-genre studies have suggested that thesis and dissertation titles have distinctive structural features in terms of their syntactic structure, rhetorical functions, and informativeness (Jalilifar/Hayati/Mayahi 2010). However, these types of titles have received very little attention, with just a few studies having been published on the matter (Soler 2018, Afful/Akoto 2010, Jalilifar 2010, Jalilifar/Hayati/Mayahi 2010, Gesuato 2009, Dudley-Evans 1984), none thus far focusing on the field of dentistry in particular. Therefore, the purpose of this paper is to help fill that gap by analyzing the linguistic structures and their functions in English-language thesis and dissertation titles in dentistry.

\section{Literature review on titles}

Titles are the very first part of any text and are important because they can encourage or discourage a reader from reading the rest of the text (Moattarian/ Alibabaee 2015, Cheng/Kuo/Kuo 2012, Jalilifar 2010, Jalilifar/Hayati/Mayahi 2010, Busch-Lauer 2000). A reader will often use a title to decide whether a text is worth reading or not. Therefore, title writing is a critical process in academic writing.

Different genres have distinct writing conventions and review processes determined by social, cultural, cognitive, and disciplinary factors. As a result, despite their common features, titles have different purposes and exhibit divergent characteristics from one genre to the other (Jalilifar/Hayati/Mayahi 2010). The title structure may also vary according to the discipline and language. Few style manuals offer guidelines for composing academic titles of research papers and theses. According to Rath (2011), these manuals need to incorporate recent research on writing so that updated guidelines can be available to members of the discourse communities.

From a general perspective, according to Swales and Feak (2014), an appropriate title should fulfill four requirements to accomplish its functions: a) it should indicate the scope of the research, b) it should introduce the topic of the research, c) it should be self-explanatory, and d) in some cases, it should indicate the nature of the study.

Cianflone (2010) suggests that writers should follow discipline-based conventions to write precise academic titles, which may manifest itself in the title by minimization (or omission of important information), over-generalization (which leads to the wrong message), and unclear message. With that purpose, he suggests a pattern that includes the topic, subjects of the study, and other relevant information (e.g., area, geographical location, and time when the research was carried out). 
Research on titles of academic genres can be classified into three groups: cross-genre studies, studies on research paper titles, and studies on student academic genres.

\subsection{Cross-genre studies}

Cianflone (2013) analyzed the state of the art of title encoding practices in three written genres commonly used in food science, namely research articles, short communications, and poster presentations. His results indicated a prevalence of nominal phrase and compound titles and a lack of question titles in the three genres. His results also showed that titles had a mean length of 15.3 words in research articles, 14.6 words in short communications, and 12 words in poster presentations.

Soler (2011) compared review and research paper titles in the biological and social sciences in both English and Spanish. She found a high frequency of nominal phrase titles. Regarding the use of punctuation, she found that in English titles colons were used to separate components of compound structures; in Spanish, commas, periods, colons, or dashes were used instead.

Gesuato (2009) analyzed the lexical density, syntactic structure, and length of titles in four genres in linguistics: dissertations, research papers, proceedings papers, and books. She found some similarities across the genres studied as well as some genre-specific features.

Soler $(2007,2009)$ studied the structural construction of research paper and review paper titles in English and Spanish in the biological and social sciences. She found a predominance of nominal phrase titles, a high frequency of fullsentence titles in research papers in the biological sciences, and a high frequency of compound titles in the social sciences.

\subsection{Studies on research paper titles}

Shahidipour and Alibabaee (2017) investigated the syntactic structures and rhetorical functions of English and Persian research papers in electrical engineering, psychiatry, and linguistics. The results showed that there were some crosslinguistic and cross-disciplinary variations in title structures in terms of components, length, and style.

Sahragard and Meihami (2016) analyzed research paper titles in the field of linguistics and found that they tended to provide information on the topic of the study as well as their method/design, results, and dataset. 
For their part, Moattarian and Alibabaee (2015) analyzed the syntactic structures of research paper titles in applied linguistics, dentistry, and civil engineering. They found that there were some discipline-specific differences in terms of title components, length, and style.

Nagano (2015) identified the structure of research paper titles in different disciplines. When comparing soft sciences and hard sciences, he found that the latter tended towards the use of longer titles, fewer multi-unit titles, more nominal phrase titles, and higher lexical density.

Cianflone (2010) analyzed the format of veterinary medicine research paper titles in terms of the presence of nominal structures, full-sentence structures, compound structures, and question structures. He found that nominal phrase titles included one-head and multi-head structures, with prepositional phrases used as post-modifiers. Compound titles consisted of two parts, generally divided by a colon. Finally, full-sentence titles consisted of a statement related to the research results, presented by the implicit use of a present tense verb, in either the affirmative or the interrogative form.

Wang and Bai (2007) analyzed the syntactic structures of medical research paper titles. They found a high frequency of a) one-unit nominal phrase titles, b) one-head, two-head, and multi-head structures, c) pre- and post-modifiers, and d) prepositional phrases used as post-modifiers.

Lewison and Hartley (2005) examined title length, the use of colons, and the number of authors in science and cancer research. They found that title length, the average number of authors per paper, and the frequency of titles with colons have tended to increase over time.

Forray and Woodilla (2005) examined research titles from three management journals in terms of the use of punctuation marks, academic terminology, word choice, and temporality expressions. They detected certain distinctive characteristics of titles that could be associated with the management discourse community.

Haggan (2004) studied the structure of research paper titles in literature, linguistics, and science. He found three different title structures: full-sentence titles, compound titles, and nominal phrase titles mainly using prepositional phrases as post-modifiers. He found pragmatic disciplinary differences and syntactic similarities in titles.

Goodman, Stephen, and Paul (2001) examined medical research paper titles. They classified titles according to the elements present, namely methods, dataset, results, conclusions, or topic only. They found a high frequency of topic-only titles, with most of the titles lacking information about study design, methods, and results.

Anthony (2001) analyzed the characteristic features of research paper titles in computing, including length, punctuation usage, word frequency, and preposi- 
tion usage. He found an average of 7.9 words per title; and in compound titles, the colon was most often used to separate their components.

Busch-Lauer (2000) compared German and English research paper titles in linguistics and medicine. Her findings showed that linguistics titles tended to be shorter than medicine titles, German titles tended to be shorter than English ones, and German medical research titles tended to involve compound structures while English medical titles tended to consist of one-unit structures.

\subsection{Studies on titles of student academic genres}

Despite the attention that has been given to full theses as a discourse genre, studies on thesis titles are relatively few. In one of the exceptions noted above, Gesuato (2009) found a high syntactic complexity in thesis titles resulting from the condensing of high-level information, and the use of technical terminology.

Although academic text titles have common features, they may differ in their communicative purposes and grammatical lexical features (Jalilifar/Hayati/ Mayahi 2010). Thesis titles need to be descriptive enough to be attractive as well as easy to remember and understand. Composing a thesis title can prove difficult for students and there is little literature that offers guidelines (Jalilifar 2010). Generally, the guidelines that do exist consist of recommendations for writing scientific paper titles in general. Dudley-Evans (1984) considers that teaching thesis titles should be based on the patterns derived from the analysis of authentic texts, theses that have been submitted and approved by juries. Even though, as noted, to date there have been no studies on thesis titles in the field of dentistry, table 1 summarizes some studies on thesis titles in other disciplines.

Table 1: Studies on thesis titles.

\begin{tabular}{lll}
\hline Authors & Area & Main findings \\
\hline Soler (2018) & $\begin{array}{l}\text { Argentine doctoral theses in 20 } \\
\text { different disciplines written in } \\
\text { Spanish }\end{array}$ & $\begin{array}{l}\text { Compound titles and nominal } \\
\text { phrase titles predominate. }\end{array}$ \\
\hline Afful/Akoto (2010) & $\begin{array}{ll}\text { Theses in the fields of literature } \\
\text { and chemistry written in English }\end{array}$ & $\begin{array}{l}\text { There are notable differences } \\
\text { across disciplines; punctuation } \\
\text { marks: such as parentheses, } \\
\text { comma, colon, hyphen, and full } \\
\end{array}$ \\
& stop are widely used. \\
\hline
\end{tabular}


Table 1: (continued)

\begin{tabular}{lll}
\hline Authors & Area & Main findings \\
\hline Jalilifar (2010) & $\begin{array}{l}\text { Theses and research articles in } \\
\text { applied linguistics written in } \\
\text { English }\end{array}$ & $\begin{array}{l}\text { There are differences between the } \\
\text { two genres, with thesis titles } \\
\text { tending to be more informative. }\end{array}$ \\
\hline $\begin{array}{ll}\text { Jalilifar/Hayati/Mayahi } \\
\text { (2010) }\end{array}$ & $\begin{array}{l}\text { Theses and research articles in } \\
\text { linguistics written in English }\end{array}$ & $\begin{array}{l}\text { Thesis titles tend to be longer and } \\
\text { more informative than research } \\
\text { articles titles. }\end{array}$ \\
\hline Gesuato (2009) & $\begin{array}{l}\text { Theses and other discourse genres } \\
\text { in linguistics written in English }\end{array}$ & $\begin{array}{l}\text { The average length of titles is 12.9 } \\
\text { words; the most frequent } \\
\text { structures are single-unit and } \\
\text { multi-unit titles, and nominal } \\
\text { phrase titles with pre- and post- } \\
\text { modifiers. }\end{array}$ \\
& $\begin{array}{ll}\text { Theses in plant biology, road } \\
\text { engineering, biological sciences, }\end{array}$ & $\begin{array}{l}\text { Nominal groups with modifiers are } \\
\text { frequently used. }\end{array}$ \\
& $\begin{array}{l}\text { and electrical and civil engineering } \\
\text { written in English }\end{array}$ & \\
\hline Dudley-Evans (1984) & & \\
& &
\end{tabular}

To sum up, discourse research has shown that titles in academic writing vary across disciplines, languages, cultures, and genres in terms of the following variables: length, punctuation marks, morphosyntactic structure, lexical choices, and semantic and pragmatic relationships between components.

\section{Methods}

To compile the dataset to be analyzed, we randomly selected the titles of 413 theses or dissertations presented between January 2000 and June 2019 at universities in twelve countries in various parts of the world. The resulting corpus consisted of 5,540 running words.

The documents were retrieved from the two most important international online thesis and dissertation databases, namely Proquest and EBSCOhost. A search of these databases was performed on July $1^{\text {st }} 2019$ using the following keywords: Dentistry OR Dental OR Oral Surgery OR Periodontology OR Stomatology OR Endodontics OR Prosthodontics. Only the titles of theses or dissertations that were written in their totality in English were included in the dataset.

Title approval and analysis were performed independently by four reviewers to avoid bias and corroborate analyses. It proved unnecessary to negotiate differing analyses because no such differences among reviewers arose. 
The corpus was examined from two complementary perspectives. On the one hand, the grammatical structure of the title (i.e., the surface morphosyntactic structure, the use of punctuation marks) and its function (i.e., the pragmatic and semantic information that the surface structure communicates) were analyzed using quantitative techniques. On the other hand, prototypical exemplars of titles were analyzed quantitatively.

For each title, the length was measured by counting the number of words. In this study, a word is defined typographically as strings of letters preceded and followed by spaces or punctuation marks. Thus compounds, hyphenated constructions, capitalized abbreviations, and numerical sequences - for example, “meta-analysis” and “CAD” and "CAM” technology - were all regarded as single words.

The structures of titles were classified into one of three categories: singleunit, multiple-unit compound, or full-sentence. A single-unit title was defined as a single string of words which expressed the research topic but did not constitute a complete sentence. A multiple-unit title was defined as a series of phrases that were separated by a punctuation mark. A full-sentence was defined as a construction usually including a subject followed by a verb in the simple present tense and a complement.

Semantically, the informativeness of titles was analyzed. Informativeness is usually expressed through words describing actions (e.g., assess, study, analysis), reporting results of the study (e.g., effectiveness, effect, association, impact), or pointing to other aspects of a study (e.g., area, scope, or method). Lexical density was also analyzed.

\section{Results}

As noted, the study analyzed titles from a quantitative and qualitative perspective. The quantitative analysis looked at basic statistical data such as title length, the use of punctuation marks, lexical density, syntactic structure, and word frequency. As part of the syntactic analysis, heads (number and types) and their modification patterns (number and types) were considered.

The qualitative analysis focused on the titles' structures and pragmatic functions. From this perspective, prototypical exemplars were analyzed considering the cultural and disciplinary context of the theses. 


\subsection{Title length}

The average length per title was 13.4 words. This result is similar to the average title lengths reported in previous studies: For thesis titles in applied linguistics 14 words (Jalifar 2010), linguistics 13 words (Gesuato 2009), and literature 13 words (Afful/Akoto 2010); for titles of systematic reviews in Spanish 14 words (Morales et al. 2020) and in English 12 words (Perdomo/Morales under review); and for titles of research papers in veterinary medicine 13-16 words (Gandur 2015), natural sciences 15 words (Soler 2007), and science 13.8 words (Haggan 2004). However, this finding differs from Morales et al. (under review), who found that the titles of dentistry theses in Spanish averaged 19 words.

Regarding the different title structures identified, similar averages were found for the different structures, ranging from 12.5 words for nominal phrase titles and 12.8 words for gerund titles, to 14.8 words for prepositional titles, 15 words for full-sentence titles, and 16.3 words for compound titles. The shortest title was only 3 words and the longest 56 words, which is a wide range $(n=53)$; however, those two values were extreme cases that each occurred only one time.

As Table 2 shows, the majority of the titles (66.8\%) varied from 10 to 20 words. $24 \%$ ( $n=99$ titles) were below 10 words in length. Long titles over 20 words were not very common in these dentistry theses and dissertations $(n=38)$, and only four titles over 30 words in length were found (1\%). This finding is not consistent with a previous study on dentistry around $80 \%$ of titles over 20 words and just $4 \%$ below 10 words.

Table 2: Distribution of titles according to number of words.

\begin{tabular}{lrr}
\hline Range & Number of titles & Percentage of all titles \\
\hline Below 10 & 99 & $24 \%$ \\
\hline Between 10 and 20 words & 276 & $66.8 \%$ \\
\hline Between 21 and 30 words & 34 & $8.2 \%$ \\
\hline More than 30 words & 4 & $1 \%$ \\
\hline Total & 413 & $100 \%$ \\
\hline
\end{tabular}

The shortest and longest titles in the dataset are reproduced respectively in (1) and (2) below ${ }^{1}$. (1) is clearly much too broad, neither communicating properly what the study is about nor including any of the features normally associated with an appropriate title (Cianflone 2010, Swales/Feak 2014). The second title, on the other hand, is grossly redundant, giving much more information than is needed. Thus both cases imply a violation of the Gricean maxim of quantity (Grice 1975). 
(1) The Torsional Truth

(2) Dental caries, periodontal disease and dental attrition: their role in determining the life span of the human dentition in Britain over the last three millennia: the medical, dental and social implications of the variable life span of the human dentition and the relevance of the findings of this study to both dental paleopathology and modern epidemiological research

\subsection{Punctuation}

As can be seen in Table 3, more than half of the titles did not include any punctuation marks. (3) exemplifies a title in which no punctuation mark is used (even omitting the mandatory apostrophe in specialists').

(3) A Qualitative Phenomenology Study of US Army Preventive Dentistry Specialists Transition of Military Education and Training to Civilian Employment

On the other hand, $48.7 \%(n=201)$ of the titles used a punctuation mark (colon, comma, dash, question mark, slash, parentheses, hyphen, or full stop) or a combination of two or more marks. The least popular mark was the full stop: it seems that authors of dental theses rarely use this punctuation in their titles. This finding is partially consistent with Hartley (2007b), who found that students and scholars preferred use colons in their titles. By contrast, previous studies on linguistics thesis and research paper titles in English (Haggan 2004, Afful/Akoto 2010, Jalilifar/Hayati/Mayahi 2010) have found a high frequency of both colons and full stops.

The most frequent mark, both alone and in combination, was the colon, which is used to relate components in compound titles, as illustrated in (4). Soler (2011) reported a similarly high frequency of colons.

(4) Mass media effects on the profession of pediatric dentistry: A survey and analysis

The second most frequent punctuation mark was the hyphen, either alone or in combination with other marks. However, most of the time it was used to form compound adjectives and compound nouns, and to indicate the range of time or age. Technically, a "dash" (-), not a hyphen (-), is used to show ranges and separate compound titles' units, though a student writer is unlikely to know this. Example (5) illustrates the use of a hyphen instead of a dash to separate the components of a compound title.

(5) Low cost, low dose, oral, neoadjuvant chemotherapy protocol in locally advanced borderline oral cancers - feasibility study 
The third was the comma, which was used to separate the elements in a list of nouns or adjectives (6) or to set off elements describing location (insitution, city, country), as in (7) or time (year). Similarly, Soler (2011) and Jalilifar, Hayati, and Mayahi (2010) likewise found a high frequency of comma use in compound titles.

(6) Knowledge, attitudes, and behaviors of federal service and civilian dentists concerning minimal intervention dentistry

(7) Factors affected to satisfaction of personnel toward operation at Department of Operative Dentistry and Endodontics, Faculty of Dentistry, Mahidol University

Question marks were found in less than 2\% of the titles. The title in (8), which combines a question and a nominal phrase in a compound title, exemplifies the use of the question mark in a title.

(8) Is There An Association Between Endodontic Pathosis and Cardiovascular Disease? A Systematic Review and Meta-analysis

The use of punctuation marks in the dataset of thesis and dissertation titles under study is summarized in Table 3.

Table 3: Punctuation marks found in the dataset of thesis and dissertation titles.

\begin{tabular}{lrr}
\hline Punctuation marks & Number of titles & Percentage of all titles \\
\hline$\emptyset$ & 211 & $51.1 \%$ \\
\hline Period & 2 & $0.5 \%$ \\
\hline Colon & 85 & $20.6 \%$ \\
\hline Comma & 24 & $5.8 \%$ \\
\hline Hyphen & 41 & $9.9 \%$ \\
\hline Dash & 3 & $0.7 \%$ \\
\hline Question mark & 8 & $1.9 \%$ \\
\hline Slash & 6 & $1.5 \%$ \\
\hline Parentheses & 5 & $1.2 \%$ \\
\hline Combinations & 29 & $7.0 \%$ \\
\hline Total & 413 & $100 \%$ \\
\hline
\end{tabular}




\subsection{Syntactic structures of titles}

The overall structure of the titles was also examined. We first divided them into two subsets, single-unit titles, consisting of one information unit, and multi-unit titles, which comprised two or more components.

We identified four syntactic structures for single-unit titles, namely nominal phrase titles, gerund phrase titles, full-sentence titles (both affirmative and question), and prepositional phrase titles. This result is similar to previous studies, such as Gesuato (2009), Jalifar (2010), Entralgo, Salager-Meyer, and Luzardo (2014), Gandur (2015), Shahidipour and Alibabaee (2017), and Adams (2019).

We found two types of compound titles: two-unit titles and three-unit titles, being the former the most frequent structure. In both cases, they used punctuation marks to separate the components (i.e. colon, full stop, question mark, or dash), which agrees with Anthony (2001) and Morales et al. (2020).

Nominal phrase titles were the most frequent structure (68.3\%), followed by compound titles $(22.5 \%)$. The other three structures accounted for a very small percentage, around $9 \%$ (gerund phrase titles $6.8 \%$, prepositional phrase titles $1.2 \%$, and full sentence titles 1.2\%). Haggan (2004), Hartley (2007a), Soler (2007), and Shahidipour and Alibabaee (2017) found similar percentages for these structures in research papers. Our finding is also consistent with the findings for theses reported in Dudley-Evans (1984), Gesuato (2009), Jalifar (2010), and Jalilifar, Hayati, and Mayahi (2010).

\section{a) Nominal phrase titles}

Nominal phrase titles were the most frequent structure (68.3\%), which is similar to previous studies (Haggan 2004, Soler 2007, Wang/Bai 2007, Nagano 2009). Following Gandur (2015), a noun phrase permits information to be compacted in an economical way. It includes structures containing some of the following components: A head, and then determiners (such as the, $a$ or an), adverbs, adjectives, or nouns located before the head which function as pre-modifiers. Prepositional phrases and non-personal verbal forms, to compact information in an economical way, are usually used as post-modifiers (Wang/Bai 2007). Contrary to Jalilifar, Hayati, and Mayahi (2010), no relative clauses (that-clauses) were found.

Similar to the findings in the studies by Wang and Bai (2007) and Jalilifar, Hayati, and Mayahi (2010), the nominal phrase titles included one-head (9), twohead (10), and multiple-head constructions (11). Titles with more than one head consist of two or more nominal phrases connected by a comma, and, or, or $v s$. 
(9) Essays on socioeconomic disparities in dental health

(10) Audio-visual distraction and stress reduction in endodontic patients

(11) Knowledge, attitudes, and behaviors of federal service and civilian dentists concerning minimal intervention dentistry

Heads mainly consisted of nominalizations and non-discipline-related words denoting the method of study, actions, or results. Modifiers provide supplementary information on the subject or area of interest and other characteristics of the study (Cianflone 2010), as illustrated by titles (12-14).

(12) The effectiveness of prophylactic etodolac on post-endodontic pain

(13) Comparison Between Two Periodontal Regenerative Procedures in Humans

(14) Peptide-guided Dental Tissue Regeneration for Oral Care

Regarding the number of heads in nominal phrase titles, we found that $70.5 \%$ were one-head titles $(n=291)$, which agrees with Wang and Bai (2007) and Gandur (2015), who found a prevalence of one-head noun phrases in medicine titles. Two-head nominal phrase titles followed with $14.3 \%(n=59)$.

We found both discipline-specific $(10,14)$ and non-discipline-specific heads $(9,11-13)$. The results show a high occurrence of non-discipline specific nouns $(60.8 \%)$, which are either general classifying words that describe the results (Gandur 2015) or nominal groups linked to the research process (Rath 2010a). This coincides with previous studies (Cheng/Kuo/Kuo 2012, Rath 2010a, 2010b, 2010c). Similar to what Wang and Bai (2007) found, most of the heads were abstract nouns.

Table 4: Types of modifiers observed in nominal phrase titles.

\begin{tabular}{lrr}
\hline Type of modifiers & Number of titles & Percentage of all titles \\
\hline Post-modifiers & 268 & $94.7 \%$ \\
\hline Post-modifiers only & 84 & $29.7 \%$ \\
\hline Pre-modifiers & 196 & $69.3 \%$ \\
\hline Pre-modifiers only & 12 & $2.9 \%$ \\
\hline Pre- + post-modifiers & 184 & $65 \%$ \\
\hline Total & $\mathbf{2 8 3}$ & $\mathbf{1 0 0} \%$ \\
\hline
\end{tabular}

Table 4 shows a high frequency of modified heads. Post-modified heads yielded the highest average (94.7\%), whereas pre-modified heads accounted for $69.3 \%$ and the combination of pre- and post-modifiers, $65 \%$. These findings are in line with Wang and Bai (2007), Nagano (2009), and Gandur (2015). However, they differ from Gesuato (2009), who found a higher frequency of pre-modifiers, 
adjectives, and nouns in linguistics theses. Examples (14) above and (15) below illustrate prototypical examples of pre-modified heads.

(15) Three-dimensional immediate post-surgery condylar displacement

The results showed a high frequency of three syntactic structures: head + postmodifiers [prepositional phrases and non-personal verbal forms, as shown in examples (9), (11), (13)]; pre-modifiers (articles, adverbs, adjectives, gerunds, nouns) + head + post-modifiers [e.g., (10), (12), (14)]; and pre-modifiers + head [e.g., (14) and (15)]. These results are similar to Wang and Bai's (2007) and Gesuato's (2009) findings for research paper and thesis titles.

The most frequent form of post-modification was the prepositional phrase $(n=268)$ or sequences of them (an average of 2 per title). Around half $(50.2 \%)$ post-modified the heads by combining prepositional phrases with non-personal verbal constructions (past and present participle clauses, to-infinitive clauses). We observed that $48.4 \%$ of the heads were pre-modified by nouns, adjectives, adverbs, or gerunds. These findings agree with Wang and Bai (2007), Gesuato (2009), Nagano (2009), and Gandur (2015).

\section{b) Compound titles}

Compound titles consisted of two or more components, generally divided by a colon (Hartley 2007a). The main section is intended to inform about the topic, while the other components offer more specific information on the topic, scope (participants, sample, environment, place, and area), or method (Cianflone 2010) [see examples (4), (5), (8), and (16) below]. Compound titles were the second most frequent construction, accounting for $22.5 \%(n=93)$, of which just three were three-unit titles like example (2). These results agree with findings on thesis (Jalilifar/Hayati/Mayahi 2010) and research paper titles in English (Soler 2011), but differ from results reported in other research paper title studies, in which about one-third of the linguistics titles were compound (Haggan 2004, Soler 2007, 2018).

(16) Mass media effects on the profession of pediatric dentistry: A survey and analysis

We found that colons, dashes, full stops, and question marks were used to separate the different components of compound titles. The colon was the most frequent (91.4\%) [see examples (4), (5), (8), (16)], followed by a dash (3.2\%), question mark (3.2\%), and full stop (2.2\%). These percentages agree with previous studies on theses (Jalilifar/Hayati/Mayahi 2010; Soler 2018) and research paper titles (Haggan 2004, Soler, 2007, 2011); in those studies, the most frequent 
punctuation mark used was the colon, and the least frequent, the dash. Our findings are in line with Hartley (2007a), who found similar results in students' and scholars' academic genres.

\section{Structural construction of compound titles}

As can be seen in Table 5, seven different structures of compound titles were found. The most frequent structure was the combination of two nominal phrases (79.1\%), followed by the combination of a gerund phrase with a nominal phrase $(8.8 \%)$, and followed in turn by the combination of a question with a nominal phrase (4.4\%).

Table 5: Structures of compound titles.

\begin{tabular}{lrr}
\hline Structure & Number of titles & Percentage of all titles \\
\hline Nominal Phrase / Nominal Phrase & 72 & $79.1 \%$ \\
\hline Gerund Phrase / Nominal Phrase & 8 & $8.8 \%$ \\
\hline Full Sentence/ Nominal Phrase & 4 & $4.4 \%$ \\
\hline Prepositional Phrase / Nominal Phrase & 3 & $3.3 \%$ \\
\hline Nominal Phrase /Full Sentence & 2 & $2.2 \%$ \\
\hline Nominal Phrase / Prepositional Phrase & 1 & $1.1 \%$ \\
\hline Nominal Phrase / Gerund Phrase & 1 & $1.1 \%$ \\
\hline Total & $\mathbf{9 3}$ & $\mathbf{1 0 0} \%$ \\
\hline
\end{tabular}

The other four structures accounted for a very small percentage $(7.7 \%)$. This result is similar to what Gesuato (2009) and Jalilifar, Hayati, and Mayahi (2010) found in linguistics theses and Gandur (2015) in research papers in veterinary medicine. Examples (17-20) below illustrate these combinations. (17) combines two nominal phrases; (18), a gerund and a nominal phrase; (19) includes a question and a nominal phrase; and (20) a prepositional phrase and a nominal phrase.

(17) Dental anxiety in a Swedish city population of women. A cross-sectional and longitudinal study of prevalence, dental care utilization, and oral and mental health factors

(18) Developing community dentistry through action learning: the actions, reflections, and learning of a clinical director

(19) Is There An Association Between Endodontic Pathosis and Cardiovascular Disease? A Systematic Review and Meta-analysis

(20) On Oral Health, Inequality, and the Erie County Poorhouse: An analysis of oral health disparities in a 19th-century skeletal population using new methodologies 


\section{Rhetorical combination of compound titles}

We found four rhetorical combinations: Topic-Scope, Topic-Method (and vice versa, Method-Topic), Question-Topic (and vice versa, Topic-Question), and Question-Method. As can be seen in Table 6, the two most frequent combinations were Topic-Method and Topic-Scope. The topic, followed by a colon, followed by the method was the most frequent construction used in compound titles. It is for this reason that Hartley (2007a; 2007b) calls these kind of titles "colonic titles".

Table 6: Rhetorical combinations observed in compound titles.

\begin{tabular}{lrr}
\hline Rhetorical combination & Number of titles & Percentage of all titles \\
\hline Topic-Method & 50 & $54.9 \%$ \\
\hline Topic-Scope & 34 & $37.4 \%$ \\
\hline Question-Topic & 4 & $4.4 \%$ \\
\hline Question-Method & 3 & $3.3 \%$ \\
\hline Total & $\mathbf{9 1}$ & $\mathbf{1 0 0} \%$ \\
\hline
\end{tabular}

\section{c) Gerund phrase titles}

The gerund phrase title, also called V-ing phrase titles, begins with a gerund (Shahidipour/Alibabaee 2017), as illustrated by (21) and (22) below. Jalilifar, Hayati, and Mayahi 2010) include it in a wide-ranging category which they label "verb phrase titles". Contrarily, Gesuato (2009) regards such structures as nominal phrase titles. However, in our case, this structure does not function as a noun, since in all cases a noun exists that could replace the verb used. These titles have a predicative function and are used to give a sense of continuity or to express activity in progress. Gerund phrase titles tend to highlight the research activity (Moattarian/Alibabaee 2015). For Nagano (2009), using this structure permits authors to emphasize an action or process over its results, as exemplified by examples (21) and (22).

(21) Evaluating an Educational Module for Training Predoctoral Dental Students in Pediatric Dentistry

(22) Evaluating a novel microbe enrichment technique to improve metagenomic analysis

Gerund phrase titles were the third most frequently identified syntactic structure in the dataset, accounting for $6.8 \%$ of the titles $(\mathrm{n}=28)$. This finding is consistent with Gesuato (2009), Jalilifar, Hayati, and Mayahi (2010), and Wang and Bai 
(2007). But it differs from Jalilifar's (2010) findings for theses (2.97\%). This percentage is also lower than that reported by Shahidipour and Alibabaee (2017), who found that $13.2 \%$ of the English titles in their data began with gerunds. In addition, these authors reported that gerund phrase titles were more frequent than full-sentence titles.

\section{d) Full-sentence titles}

These titles, also called conclusive titles, take the form of a statement related to the research results or conclusions, as exemplified by (23). They comprise one head, referring to the object of study, followed by a present tense declarative verb, or take the form of a full-sentence-question (24), which agrees with Soler (2007, 2018). For Sisó (2009), due to their high lexical density, authors can use fullsentence titles to provide a lot of information about both the study and its results in a concise fashion.

(23) Polyamines Mitigate Antibiotic Inhibition of A. actinomycetemcomitans Growth

(24) Do systematic reviews and meta-analyses, published in the dental literature, comply with the QUORUM and PRISMA statements?

In our dataset, however, the full-sentence construction was one of the least preferred structures $(1.2 \% ; n=5)$, with only two full-sentence conclusive titles (23) and three question titles (24). The low frequency of this type of title confirms Haggan's (2004) findings for linguistics research papers titles and Soler's (2018) for multidisciplinary thesis titles in Spanish. However, it disagrees with both Soler (2007), who regarded the use of full-sentence titles as a peculiarity of research papers in biology, and Cianflone (2010), who found a higher frequency of question titles. Our results also contradict those of Berkenkotter and Huckin (1995), who found an increasing trend towards the use of full-sentence titles in academic genres. However, based on our results, Berkenkotter and Huckin's conclusion may be a characteristic of science titles in general, but not dentistry titles in particular.

\section{e) Prepositional phrase titles}

This kind of title begins with a preposition, as exemplified by (25). Yakhontova (2002) calls them "incomplete sentence titles". They were equally rare in our dataset, also accounting for only $1.2 \%$ of the titles $(n=5)$, which is consistent with Anthony (2001) and Gesuato (2009), who found similar results for research 
paper and thesis titles, respectively. However, this percentage is lower than Jalilifar, Hayati, and Mayahi’s (2010) findings for theses (4.68\%).

(25) Towards a 4-D spatial and temporal model of human enamel biomineralisation

\subsection{Semantic analysis}

\section{a) Informativeness}

Based on Jalilifar, Hayati, and Mayahi (2010), the semantic content of titles in our corpus was analyzed through their informativeness. We considered words that described actions [e.g., clinical trial, study, analysis, evaluation, as in (26) and (27) below], indicated results of the study [e.g., association, effects, effectiveness, as in (28) and (29)], or identified the method (i.e., the design or approach), sample (i.e., the participants, context, or place where the research was carried out), and area of the research [i.e., orthodontics or endodontics, as in (30)].

(26) A Qualitative Phenomenology Study of US Army Preventive Dentistry Specialists Transition of Military Education and Training to Civilian Employment

(27) An examination of constructs associated with dental anxiety and avoidance among adults seeking dental care

(28) The Association between Early Dental Visits, Dental Outcomes, and Oral HealthRelated Quality of Life in West Virginia Children

(29) The effect of Medicaid dental coverage on dental care utilization among older Americans

(30) Development of a cultural competence assessment for pediatric dentistry

Table 7: Information provided in the titles.

\begin{tabular}{lrr}
\hline Element of research highlighted & Number of titles & Percentage of all titles \\
\hline Sample (the object of study) & 192 & $46.5 \%$ \\
\hline Method & 108 & $26 \%$ \\
\hline Result & 293 & $70.9 \%$ \\
\hline Action & 206 & $49.9 \%$ \\
\hline Dental specialty & 268 & $64.9 \%$ \\
\hline
\end{tabular}

As can be seen in Table 7, titles that informed about the specific field of dentistry, the action carried out, and the results were most frequent. Titles that identified the sample (participating patients, animal subjects, and or places where the 
research was carried out) accounted for $46.5 \%$. Finally, titles that identified the method, whether at the beginning or the end of the title, were the least common ( $26 \%, n=108)$. This result reflects the requirements recommended in previous studies for an acceptable title (Swales/Feak 2014, Jalilifar/Hayati/Mayahi 2010).

Contrary to what Jalilifar, Hayati, and Mayahi (2010) found in their study, the area (dental specialties) was frequently included. $26 \%$ included information on the method or design. These findings are partially in line with previous studies (Sahragard/Meihami 2016, Goodman/Stephen/Paul 2001), which found that titles tended to provide information on method/design and topic.

\section{b) Nominalization}

Nominalization consists of using a noun instead of a verb to express conceptual information related to actions, processes, procedures, properties, and practices. This is exemplified in (31) below, where instead of "the association between" the author could as easily have employed a construction including "are associated with". Nominalization was used in $53 \%$ of the titles in this dataset $(n=220)$. As noted by Maglie (2009), using nouns permits the author to pack a great amount of information into fewer words. As dentistry scholars do not seem to use verbs in titles, the use of nominalization implies a loss in value on the part of verbs. Using verbal constructions lends itself to informing about results and conclusions, which is not well perceived in dentistry.

(31) The Association between Early Dental Visits, Dental Outcomes, and Oral HealthRelated Quality of Life in West Virginia Children

\section{c) Lexical density}

In this set of dentistry thesis and dissertation titles we found an average lexical density of $73 \%$, meaning that there was a higher percentage of content words (an average of 10) compared to the number of function words (an average of 4). Similar results were reported by Gesuato (2009) for linguistics theses, Afful and Akoto (2010) for theses, Alcaraz-Ariza and Salager-Meyer (2012) for research papers in medicine, and Gandur (2015) for veterinary medicine research papers. The average lexical identity found here is slightly higher than that found by Morales et al. (under review) for dentistry theses in Spanish (60\%).

Sisó (2009) points out that high lexical density allows the author to provide a lot of information about the study in a concise fashion. High lexical density is illustrated by titles (32) and (33), both taken from our dataset. 
(32) Pre-doctoral implant dentistry education: Trends, issues, and perspectives

(33) Three-dimensional immediate post-surgery condylar displacement

\section{Conclusions}

The titles of dental theses or dissertations echo the main content of the full document and make an important contribution to fulfilling their communicative purposes. Thus, when writing titles, student researchers need to consider the scope, content area, and context of the research, as well as the title's morphosyntactic structure and level of informativeness.

The results of our analysis of a small corpus of 413 randomly selected theses or dissertations related to the field of dentistry show that nominal phrases are the main syntactical construction used, both in one-unit titles and in compound titles, which suggests that this grammatical structure is very important in dentistry theses. Moreover, the combination of two nominal phrases is the most frequent structure of compound titles. In both cases, prepositional phrases and non-personal verbal phrases are most frequently used as post-modifiers, and adjectives, nouns and adverbs as pre-modifiers.

Our results also show that, in terms of length, thesis titles in dentistry share some features with other studies. Though they are longer than research paper titles in disciplines other than dentistry, their length is similar to the titles of dentistry systematic reviews in Spanish and English, and English theses in general, but shorter than dentistry thesis titles in Spanish.

Concerning the use of heads, dental thesis titles prefer one-head nominal phrases, which include non-discipline specific nouns as the most frequent head type. They comprise nouns related to method, words that describe results, and words that describe the activities carried out.

Regarding the modification features of dental thesis titles, our results show a high frequency of one or two post-modifiers, with the prepositional group being the most frequent syntactical structure used as a modifier.

As can be inferred from these results, titles in English dental theses are informative and very precise; stylistic and rhetorical features, such as hedging, vagueness, and metaphors are not used, which is also the case of titles from other disciplines reported in previous studies.

These findings suggest some cross-genre, cross-cultural, and cross-disciplinary differences, which implies that dentistry thesis titles have specific features that should be taught to help both student researchers and teachers. On the one hand, dental students could use the structure of the titles reported as reference models when writing their theses. They could learn to manage the different aspects 
analyzed in this study, such as title length, lexical density, morphosyntactic structure, and their pragmatic functions, to successfully defend their theses and gain membership in their discourse community (Jalilifar/Hayati/Mayahi 2010).

On the other hand, our findings could be included in academic writing courses and workshops, at either the undergraduate or postgraduate level. Furthermore, thesis advisors, supervisors, as well as directors and members of the examining committee could use our findings to inform their guidance and assessment of theses. In more general terms, this would allow them to support their teaching and evaluation practices with discipline-based evidence.

Several issues merit further exploration. Further studies could examine titles from a cross-disciplinary, cross-language, and cross-genre perspective by comparing the key dentistry discourse genres titles (theses, systematic reviews, case reports, and research papers) in different languages (English and Spanish, for example) and contrasting dentistry with other disciplines (such as medicine or linguistics).

Acknowledgments: This research project received funding from the Scientific, Humanistic, Technological and Arts Development Council of the Universidad de Los Andes (ULA), in Mérida, Venezuela, code 0-307-15-06-A, and from the Carolina Foundation, with a postdoctoral fellowship at Universitat Pompeu Fabra, Barcelona, Spain, 2017-2018.We extend our gratitude to Noomen Belmechri, professor at the Universidad de Los Hemisferios (Quito, Ecuador), and Jhon Rangel, Department of Public Health Sciences, Health Systems and Policy, Karolinska Institutet (Stockholm, Sweden), for their recommendations regarding a preliminary version of this paper.

\section{References}

Adams, Sue (2019): “Empowering and motivating undergraduate students through the process of developing publishable research". Frontiers in Psychology 10, 1-4.

Afful, Joseph (2017): “A linguistic analysis of conference titles in applied linguistics". International Journal of Foreign Language Teaching and Research 5(18), 11-25.

Afful, Joseph, / Akoto, Osei Yaw. (2010): “Cross-disciplinary study of dissertation titles: The case of a university in Ghana". Journal of the IATEFL 4-19.

Alcaraz-Ariza, María / Salager-Meyer, Françoise (2013): “Análisis contrastivo de los títulos en los artículos de investigación de neurología redactados en español e inglés”. LSP JournalLanguage for Special Purposes, Professional Communication, Knowledge Management and Cognition 3(2), 27-50.

Anthony, Laurence (2001): “Characteristic features of research article titles in computer science". IEEE Transactions on Professional Communication 44(3), 187-194. 
Basturkmen, Helen (2009): "Commenting on results in published research articles and master's dissertations in language teaching”. Journal of English for Academic Purposes 8(4), 241-251.

Berkenkotter, Carol / Huckin, Thomas (1995): Genre Knowledge in Disciplinary Communication: Cognition/Culture/Power. Hillsdale, NJ: Lawrence Erlbaum.

Bunton, David (1998): Linguistic and textual problems in Ph.D. and M.Phil Theses: An analysis of genre moves and metatext. Unpublished doctoral thesis. Hong-Kong: University of Hong-Kong.

Bunton, David (2005): “The structure of Ph.D. conclusion chapters". Journal of English for Academic Purposes 4, 207-224

Busch-Lauer, Ines (2000): Titles of English and German research papers in Medicine and Linguistics. En A. Trosborg (ed.), Analysing professional genre (77-94). Amsterdam: John Benjamin.

Cheng, Stephanie / Kuo, Chih-Wei / Kuo, Chih-Hua (2012): "Research article titles in applied linguistics". Journal of Academic Language and Learning 6(1), 1-14.

Cianflone, Eugenio (2010). "Scientific titles in Veterinary Medicine research papers". English for Specific Purposes World 9(30), 1-8.

Cianflone, Eugenio (2012): “Titles in Veterinary Medicine research articles”. Círculo de Lingüística Aplicada a la Comunicación 52, 3-20.

Cianflone, Eugenio (2013): "Framing research in food science: The state of the art on research article, short communication and poster presentation titles". Revista de Lenguas para Fines Específicos 19, 269-286.

Cotos, Elene, Huffman, Sarah, / Link, Sthephanie (2017): “A move/step model for methods sections: Demonstrating rigour and credibility". English for Specific Purposes 46, 90-106.

Dudley-Evans, Tony (1984): A preliminary investigation of the writing of dissertation titles. In Gregory James (ed.), The ESP classroom: Methodology, materials, expectations (pp. 40-46). London: Exeter Linguistic Studies.

Entralgo, Johanna. Salager-Meyer, Françoise/ Luzardo, Marianela (2014): “Títulos de artículos de investigación científica escritos en inglés: un estudio interdisciplinario”. Núcleo 26(31), 75-100.

Flowerdew, John / Forest, Richard. (2009): Schematic structure and lexico-grammatical realization in corpus-based genre analysis: the case of research in the Ph.D. literature review. In Magie Charles / Susan Hunston / Diane Pecorari (Eds.), Academic writing: At the interface of corpus and discourse (pp. 15-36). London: Continuum.

Flowerdew, Lynne (2015): “Using corpus-based research and online academic corpora to inform writing of the discussion section of a thesis". Journal of English for Academic Purposes 20, 58-68.

Forray, Jeanie / Woodilla, Jill (2005): “Artefacts of Management Academe: A discourse analysis of temporality in journal titles”. Time \& Society, 14(2-3), 323-339.

Gandur, Analía (2015): Titles in research and review articles in veterinary medicine: a corpusbased study. Master thesis, Universidad de Córdoba, Córdoba, Spain.

Gesuato, Sara (2009): Encoding of information in titles: Practices across four genres in Linguistics. En Christopher Taylor (ed.), Ecolingua: the role of E-corpora in translation and language learning (pp. 127-157). Trieste: Ecolingua.

Goodman, Richard / Thacker, Stephen / Siegel, Paul (2001): "What's in a title? A descriptive study of article titles in peer-reviewed medical journals". Science Editor 24(3), 75-78. 
Grice, Paul (1975): Logic and conversation. In Maite Ezcurdia \& Robert Stainton (Eds.), Thesemantics-pragmatics boundary in philosophy (pp. 41-58). New York: Routledge.

Haggan, Madeline (2004): “Research paper titles in literature, linguistics and science: Dimensions of attraction". Journal of Pragmatics 36(2), 293-317.

Hartley, James (2007a): Colonic titles. Journal of the European Medical Writers Association 16(4), 147-149.

Hartley, James (2007b): “Planning that title: Practices and preferences for titles with colons in academic articles". Library \& Information Science Research 29(4), 553-568.

Hawes, Thomas / Thomas, Sarah (1997): “Tense choices in citations”. Research in the Teaching of English 31(3), 393-414.

Hewitt, Elaine / Lago, Angel Felices (2010): “Academic style and format of doctoral theses: The case of the disappearing discussion chapter”. Ibérica 19, 19-140.

Jalilifar, Alireza (2010): "Writing titles in applied linguistics: A comparative study of theses and research articles". Taiwan International ESP Journal 2(1), 27-51.

Jalilifar, Alireza / Hayati, Abdolmajid, / Mayahi, Nadia (2010): “An exploration of generic tendencies in Applied Linguistics titles". Journal of Faculty of Letters and Humanities 5(16), 35-57.

Lee, Joseph / Casal, Elliott (2014): "Metadiscourse in results and discussion chapters: A crosslinguistic analysis of English and Spanish thesis writers in engineering". System 46, 39-54.

Lewison, Grant / Hartley, James (2005): "What's in a title? Numbers of words and the presence of colons". Scientometrics 63(2), 341-356.

Maglie, Rosita (2009): Understanding the language of Medicine. Milan: Aracne.

Malcolm, Lois (1987): What rules govern tense usage in scientific articles? English for specific Purposes 6(1), 31-43.

Moattarian, Aasa / Alibabaee, Ahmad (2015): "Syntactic structures in research article titles from three different disciplines: Applied Linguistics, Civil Engineering, and Dentistry”. Journal of Teaching Language Skills 34(1), 27-50.

Morales, Oscar / Perdomo, Bexi / Izarra, Élix / Cassany, Daniel (under review): “Estructura retórica de revisiones sistemáticas odontológicas publicadas en español”. Revista CLAC.

Morales, Oscar / Perdomo, Bexi / Cassany, Daniel / Izarra, Élix (2019): “Estructura retórica de tesis y trabajos de grado en la odontología hispanoamericana”. Revista Íkala.

Morales, Oscar / Perdomo, Bexi / Cassany, Daniel / Izarra, Élix (2020): “Estructuras morfosintácticas y funciones retóricas de títulos de revisiones sistemáticas publicadas en español en revistas odontológicas: un análisis de género discursivo". Panacea, 51.

Morales, Oscar / Perdomo, Bexi / Cassany, Daniel / Tovar, Rosa María / Izarra, Élix (under review): "Títulos de tesis de odontología en español: estructura genérica y rasgos lingüísticos”. Revista de Lingüística y Lenguas Aplicadas.

Nagano, Robin Lee (2009): Variety in Titles: Academic Writing in Economics. A XVIII. Magyar Alkalmazott Nyelvészeti Kongresszus elõadásai Balassi Intézet, Budapest, 2008. Április 3-5. (978-992). Balassi Intézet, Budapest: MANYE.

Nagano, Robin Lee (2015): "Research article titles and disciplinary conventions: A corpus study of eight disciplines". Journal of Academic Writing 5(1), 133-144.

Nimehchisalem, Vahid / Tarvirdizadeh, Zahra / Paidary, Sara Sayed / Hussin, Nur (2016): "Rhetorical moves in problem statement section of Iranian EFL postgraduate students' theses". Advances in Language and Literary Studies 7(4), 173-180.

Paltridge, Brian (1997): Genre, frames and writing in research settings. Amsterdam: John Benjamins Publishing. 
Paltridge, Brian / Starfield, Sue (2007): Thesis and dissertation writing in a second language: $A$ handbook for supervisors. London: Routledge.

Paltridge, Brian / Starfield, Sue / Ravelli, Louise / Tuckwell, Kathryn (2012): “Change and stability: Examining the macrostructures of doctoral theses in the visual and performing arts". Journal of English for Academic Purposes 11(4), 332-344.

Parry, Sharon (1998): “Disciplinary discourse in doctoral theses”. Higher Education 36(3), 273-299.

Perdomo, Bexi / Morales, Oscar (under review): “Syntactic Structures and Rhetorical Functions of Dental Systematic Review titles in English”. Journal of Research in Language.

Rath, Alex (2010a): "Temporal function of research process nominal groups in the English titles". English for Specific Purposes World 31(10), 1-27.

Rath, Alex (2010b): "Dual function of first position nominal groups in research article titles: Describing methods and structuring summary". Research in Applied Linguistics 1(2), 5-23.

Rath, Alex (2010c): "A discourse analysis of first position nominal groups in research article titles”. Taiwan International ESP Journal 2(1), 85-104.

Rath, Alex (2011): “A Discourse Analysis of Manuals of Style: The Specification of Function and Structure for Composition of Research Article Titles". Journal of Research in Applied Linguistic Studies (RALS) 2(2), 3-17.

Sahragard, Rahman / Meihami, Hussein (2016): “A diachronic study on the information provided by the research titles of applied linguistics journals”. Scientometrics 108(3), 1315-1331.

Samraj, Betty (2013): “Form and function of citations in discussion sections of master's theses and research articles". Journal of English for Academic Purposes 12(4), 299-310.

Shahidipour, Vahid / Alibabaee, Ahmad (2017): "Syntactic structures and rhetorical functions of Electrical Engineering, Psychiatry, and Linguistics research article titles in English and Persian: A Cross-linguistic and Cross-disciplinary Study". Journal of Teaching Language Skills 36(1), 145-175.

Sisó, Mercedes (2009): “Titles or headlines?: Anticipating conclusions in biomedical research article titles as a persuasive journalistic strategy to attract busy readers". Miscelanea: A Journal of English and American Studies 39, 29-54.

Soler, Viviana (2007): “Writing titles in science: An exploratory study”. English for Specific Purposes 26, 90-102.

Soler, Viviana (2009): “Títulos científicos en lengua española: Estudio exploratorio”. Lebende Sprachen 54(2), 50-58.

Soler, Viviana (2011): “Comparative and contrastive observations on scientific titles written in English and Spanish”. English for Specific Purposes 30(2), 124-137.

Soler, Viviana (2018): "Estudio exploratorio de títulos de tesis doctorales redactados en lengua española”. Lebende Sprachen 63(2), 374-392.

Soler-Monreal, Carmen / Carbonell-Olivares, María, / Gil-Salom, Luz (2011): “A contrastive study of the rhetorical organisation of English and Spanish Ph.D. thesis introductions”. English for Specific Purposes 30(1), 4-17.

Swales, John (1990): Genre Analysis: English in Academic Research Settings. Cambridge: Cambridge University Press.

Swales, John (2004): Research Genres: Explorations and Applications. Cambridge: Cambridge University Press.

Swales, John / Feak, Christine (2012): Academic writing for graduate students: Essential tasks and skills. Ann Arbor: University of Michigan Press. 
Thompson, Paul (2001): A pedagogically-motivated corpus-based examination of Ph.D. theses: Macrostructure, citation practices and uses of modal verbs. Unpublished doctoral thesis. London: University of Reading.

Trafford, Vernon / Leshem, Shosh, / Bitzer, Eli (2014): “Conclusion chapters in doctoral theses: some international findings”. Higher Education Review 46(3), 52-80.

Wang, Yan, / Bai, Yongquan (2007): “A corpus-based syntactic study of medical research article titles". System 35(3), 388-399.

Yakhontova, Tatyana (2002): Titles of conference presentation abstracts: A cross-cultural perspective. In Eija Ventola / Ceila Shalom / Susan Thompson (Eds.), The language of conferencing (277-300). Frankfurt: Peter Lang.

Yang, Ruiying / Allison, Desmond (2003): “Research articles in applied linguistics: Moving from results to conclusions". English for Specific Purposes 22, 365-385. 